\title{
Integrated Supply Chain of Supplier and Retailer for Stochastic Demand
}

\author{
Sunil Tiwari ${ }^{a}$, Chandra K. Jaggi ${ }^{b}$ and Shib Sankar Sana ${ }^{c, d}$ \\ ${ }^{a}$ The Logistics Institute - Asia Pacific, National University of Singapore \\ 21 Heng Mui Keng Terrace, 119613 Singapore, Singapore \\ ${ }^{b}$ Department of Operational Research, University of Delhi \\ Delhi, India \\ ${ }^{c}$ Kishore Bharati Bhagini Nivedita College \\ 700060 Kolkata, India \\ ${ }^{d}$ Department of Mathematics, Bhangar Mahavidyalaya \\ Bhangar, India \\ E-mail: sunil.tiwari047@gmail.com \\ E-mail: ckjaggi@yahoo.com \\ E-mail(corresp.): shib_sankar@yahoo.com
}

Received October 19, 2017; revised September 6, 2018; accepted September 9, 2018

\begin{abstract}
This article deals with a two-stage supply chain comprising of the retailer and the supplier in which demand of the end customers follows news-vendor type demand. The setup costs, purchasing and procurement costs are dependent on lot sizes. The mathematical models for continuous and discrete variables of the chain are analyzed mathematically to maximize the expected average profits of individual and the collaborating systems. As our study suggests that collaborating system is always better than the decentralized system for known distribution cases, we also optimize the joint profit of the retailer and the supplier for a distribution free case which is implemented for unknown distribution. Finally, numerical examples of the demand patterns are illustrated to justify the proposed model. The punctual research directions from the proposed model are also provided in the conclusion section.
\end{abstract}

Keywords: supply chain, buyback, distribution, distribution free.

AMS Subject Classification: 90B05.

\section{Introduction}

The game theory is an elegant method to optimize the inventory control and management problems in a given economy among other applications in decision making problems. It is glowing premeditated by the researchers as well

Copyright (c) 2018 The Author(s). Published by VGTU Press

This is an Open Access article distributed under the terms of the Creative Commons Attribution License (http://creativecommons.org/licenses/by/4.0/), which permits unrestricted use, distribution, and reproduction in any medium, provided the original author and source are credited. 
as practitioners of supply chain management. A supply chain is a network of industries/firms that procures final products from raw materials and components which are delivered to the consumers. In a decentralized supply chain system, firms/industries are independent and self-interested entities who maximize their own profits independently. In this case, Stakellberg approach is applied to characterize the supply chain. On the other hand, the centralized supply chain is controlled by a central planner consisting of all members of the chain who is skilled in controlling all decisions. In this coordinating system, total profit of the chain is shared by the players of the chain according to their contributions/investments in the business. Munson and Rosenblatt [13] recommend coordination using quantity discounts on both ends of supply chain of supplier-manufacturer and retailer to dwindle costs compared to concentration on lower end only. Park and Keh [17] study game theoretic analysis of price and profit distribution in hybrid channel system. Yao at al. [32] locate the optimal order quantity of the retailer and buy-back price of the manufacturer in direct channel. Wee and Yang [31] propose an optimal heuristic solution of a distribution network of the single-producer, multi-distributors and multi-retailers inventory system. Jaber et al. [8] develop the model of Munson and Rosenblatt [13] in view of discount dependent demand and profit sharing mechanism among the members of the chain. Lo et al. [11] present the multiple deliveries system in an integrated production-inventory model of single manufacturer and single retailer assuming variable deterioration rate, partial backordering and inflation in an imperfect production processes.Chung and Wee [6] study a collaborative production-inventory model with partial backordering and inflation in an imperfect manufacturing system of single manufacturer and single retailer for Weibull deteriorating items. In their model, they mention that selling price strategies, warranty policy of free replacement, inspection policy and stock display of the products play an important role to attract the customers more. Van der Veen et al. [29] investigate a multi-echelon supply chain among the downstream and upstream entities applying new type of revenue sharing contract mechanism. Taleizadeh et al. [27] minimize the expected total cost of an EPQ (Economic Production Quantity) model considering random defective rate of production with limited production and service level capacity and failure of the repair of defective items. Cai [1] focuses on the impact of channel structures and channel coordination on the supplier, retailer and the entire supply chain in two single channel and two dual-channel systems. Sarkar [21] develops a production-inventory model in a two-echelon supply chain system for probabilistic deteriorating products. Sarkar and Majumder [23] explore an integrated vendor-buyer model based on probability distribution of lead time demand. They analyze their model for normal distribution and distribution free cases. Cardenas-Barron et al. [4] propose a heuristic algorithm for a multiproduct EPQ model of the integrated system of vendor and buyer with JIT (just-in-time) philosophy and budget constraint. Taleizadeh et al. [26] maximize total profit of two-stage supply chain comprising of one vendor and several non-competing retailers where the effect of deterioration on raw materials and finished products are considered. They observe optimal retail prices, replenishment frequency of raw materials, replenishment cycle of the product and pro- 
duction rate in order to achieve maximum profit of the chain. Khanra et al. [10] compare between the cases of inventory followed by shortages and shortages followed by inventory models for variable demand rate of the end customers. Tayyab and Sarkar [28] present a manufacturing EPQ model of imperfect multistage production system considering an uncertain defective rate in a cleaner multi-stage lean production system. Khan et al. [9] analyze the joint cost of two echelon (vendor-buyer for single product) supply chain in the light of variable lead time, learning in production and screening errors of nonconforming quality products. Panda et al. [16] investigate the channel coordination using by backward and forward hybrid contract-bargaining processes in order to find out the optimal benefit sharing among the manufacturer, multiple distributors and multiple retailers' supply chain. Several authors have studied two-layer supply chain models assuming different features in their models. Among them, the research works of Garcia-Laguna et al. [3], Shah and Shukla [25], Shah et al. [24], Cardenas-Barron et al. [2,3], Sana [20], Panda [14,15], Chung et al. [7], Sarkar [22] should be mentioned.

The news-vendor problem is one of the classical inventory model for uncertain demand of the customers. In this structure, overstock and under-stock are balanced so that the expected average cost is minimized. It has wide range of implications to control and manage inventory in organizations/enterprises like as food industries, fashion goods industries in a particular season, airline, hospitality, among others. Petruzzi and Dada [18] study a comprehensive review of newsboy problem where random demand is partly dependent on varying selling price. Chen and Chuang [5] develop the newsboy problem incorporating shortage-level constraint. Wang [30] makes some remarks on the optimal order quantity and reorder point for uncertainties of supply and demand. Sana [19] analyzes a stochastic EOQ (economic order quantity) model over finite time horizon where demand is random price sensitive. Ma et al. [12] suggest the optimal ordering policies of a loss-averse news-vendor with supply and demand uncertainties.

In this proposed article, we consider a three-node supply chain consisting of one supplier, a retailer and end customers. The demand of end customers is assumed to be random variable (news-vendor type) with a probability density function. At the beginning of a single period, the retailer is interested in determining an optimal stock policy to satisfy the customer's demand for a single product. As the demand is uncertain, overstock and under-stock of inventory are considered in the expected average profit of the retailer. The over stock, i.e., unsold items, is buyback to the supplier at a salvage value which is less than the purchasing price of the items. Besides it, setup cost, purchasing cost and selling price are assumed to be linear decreasing functions of order quantities respectively. As a result, the expected profit of the retailer is a function of order quantity $(\mathrm{Q})$ only. At the supplier, the demand of the retailer is $\mathrm{Q}$ and no shortage is considered because the replenishment size $(\mathrm{R})$ of the supplier is instantaneously infinite, i.e., sufficient quantities are available at the market. The unsold items at each stage (i.e., supplier and retailer) are buyback to the predecessor members of the chain. The expected average profit of the supplier includes setup cost, inventory holding cost, payment of unsold item and 
salvage value of unsold item. The purchasing cost of the supplier is a function of replenishment size $(\mathrm{R})$. Hence, it is a function of $(\mathrm{R}, \mathrm{Q})$. The continuous and discrete distributions are compulsory for uncertain demand of the end customers. In our model, decentralized and centralized supply chain between supplier and retailer are compared for both the distribution and distribution free cases.

Rest of the paper is organized as follows. The assumptions and notations are provided in Section 2. Section 3 contains mathematical formulation and analysis of the proposed model. Numerical analyses of continuous and discrete cases are illustrated in Section 4. Section 5 concludes the contribution and future research works of the paper.

\section{Fundamental assumptions and notations}

\subsection{Assumptions}

The following assumptions and notations are assumed to depict the proposed model.

i) Single supplier and single retailer are the members of the chain.

ii) Shortage is allowed at the retailer and totally backlogged.

iii) Selling prices and cost prices at each stage are decreasing functions of the lot sizes.

iv) Set up cost at the retailer is directly proportional to the lot size. It includes packaging cost, price labeling cost, shelf cost, etc.

v) Set up cost of the supplier includes fixed cost and cost per unit for packaging and price labeling.

vi) The unsold items at the retailer are buyback to the supplier at a salvage price less than the purchasing price. Also, the returned items to the supplier have salvage value at the supplier.

vii) Lead time and supply disruptions at each stage are neglected.

\subsection{Notation}

The following notations are used to develop the model: $x$-random demand of the end customers, $f(x)$ - probability density function of $x$ with mean $(\mu)$ and standard deviation $(\sigma), Q$ - order quantity of the retailer, $R$ - replenishment size of the supplier, $p(x)$ - selling price per unit item of the retailer, $w(Q)$ selling price per unit item of the supplier, $C(R)$ - purchasing/procurement cost per unit item of the supplier, $a_{r}$ - set up cost per unit item at the retailer, $C_{s}$ - shortage cost per unit item, $a_{1}$ - fixed set up cost per cycle of the supplier, $a_{2}$ - set up cost per unit at the supplier, $b_{r}(<w(Q))$ - salvage value per unsold item at the retailer, $b_{s}\left(<b_{r}\right)$ - salvage value per unsold item at the supplier, $\pi_{R}$ - expected average profit of the retailer, $\pi_{S}$ - expected average profit of the 
supplier, $\pi_{C}$ - expected average profit of the joint/collaborative system, $q_{i}-$ number of items for discrete demand of the end customers, $f_{i}$ - probability of occurrence of $q_{i} \forall i \in(1,2,3, \ldots), q_{j}$ - order quantity of the retailer, $k$ - varying scale parameter such that $R=k j$.

\section{The model}

The demand of end customers is random variable $x$ that follows the probability density function $f(x)$ such that $\int_{-\infty}^{+\infty} f(x) d x=1$. As demand of the end customers is uncertain in nature, the overstock and understock may occur. The over stock at the retailer is buyback at salvage value $b_{r}$ per unit item. The shortage at the retailer is fully backlogged and a penalty is charged for the shortage. It includes profit another cost for loss of goodwill of the retailer. Let $Q$ is the lot size of the retailer and $R$ is the replenishment size of the supplier. Quite often, the selling price and purchasing costs decrease with lot sizes. In this case, the selling prices are as follows:

$$
\begin{aligned}
& p(x)=\alpha_{1}-\beta_{1} x, \forall x<\alpha_{1} / \beta_{1}, \\
& w(Q)=\alpha_{2}-\beta_{2} Q, \forall Q<\alpha_{2} / \beta_{2}, \\
& C(R)=\alpha_{3}-\beta_{3} R, \forall R<\alpha_{3} / \beta_{3} .
\end{aligned}
$$

Here, $\alpha_{i}(i=1,2,3)$ are prices per unit item at the retailer and supplier respectively. The parameters $\beta_{i}(i=1,2,3)$ are scale parameters. In this supply chain, the following two cases may arise as demand of the end customers is uncertain.

Case-I: When stock out situation does not occur, i.e., $x \leq Q$. In this situation, the expected average profit of the retailer is $\pi_{R}$ is equal to the expected selling price minus expected purchasing cost minus expected set up cost and plus salvage value of unsold items

$$
\pi_{R}=\int_{-\infty}^{Q} p(x) x f(x) d x-w(Q) \int_{-\infty}^{Q} Q f(x) d x-a_{r} \int_{-\infty}^{Q} x f(x) d x+b_{r} \int_{-\infty}^{Q}(Q-x) f(x) d x .
$$

Similarly, the expected average profit of the supplier is

$$
\begin{gathered}
\pi_{S}=\left[(w(Q)-C(R)) Q-\frac{1}{2} h_{s} R-a_{1} Q-\frac{a_{2} Q}{R}\right] \int_{-\infty}^{Q} f(x) d x \\
-b_{r} \int_{-\infty}^{Q}(Q-x) f(x) d x+b_{s} \int_{-\infty}^{Q}(Q-x) f(x) d x .
\end{gathered}
$$

Case-II: When shortage occurs, i.e., $x \geq Q$. In this case, demand of the end customers exceeds inventory. The expected profit of the retailer is

$$
\pi_{R}=\int_{Q}^{\infty} p(x) x f(x) d x-w(Q) \int_{Q}^{\infty} Q f(x) d x-a_{r} \int_{Q}^{\infty} x f(x) d x-C_{s} \int_{Q}^{\infty}(x-Q) f(x) d x .
$$

The expected profit of the supplier is

$$
\pi_{S}=\left[(w(Q)-C(R)) Q-\frac{1}{2} h_{s} R-a_{1} Q-\frac{a_{2} Q}{R}\right] \int_{Q}^{\infty} f(x) d x .
$$


Now, combining the Cases I and II, we have the total expected average profit of the retailer and supplier as follows:

$$
\begin{aligned}
\pi_{R}= & \int_{-\infty}^{\infty} p(x) x f(x) d x-w(Q) \int_{-\infty}^{\infty} Q f(x) d x-a_{r} \int_{-\infty}^{\infty} x f(x) d x \\
& +b_{r} \int_{-\infty}^{Q}(Q-x) f(x) d x-C_{s} \int_{Q}^{\infty}(x-Q) f(x) d x \\
\pi_{S}= & (w(Q)-C(R)) Q-\frac{h_{s} R}{2}-a_{1} Q-\frac{a_{2} Q}{R}-\left(b_{r}-b_{s}\right) \int_{-\infty}^{Q}(Q-x) f(x) d x .
\end{aligned}
$$

Now, our objective is to analyze the decentralized and centralized supply chain as follows:

\subsection{Decentralized supply chain}

In this system, the members of the chain are self interested. They maximize their own profit independently. In such system, Stakelberg approach is applied to solve the problems. In this approach, one member is decision maker and other members of the chain are followers. Here, retailer is the decision maker and supplier is the follower of the retailer. The retailer determines optimal lot size $Q$ to maximize expected profit $\pi_{R}(Q)$. Then supplier maximizes his/her expected profit $\pi_{S}$ and finds out an optimal replenishment size $R$. Substituting equation (3.1) and (3.2) in equation (3.4), we have

$$
\begin{aligned}
\pi_{R}(Q) & =\left\{\alpha_{1} \mu-\beta_{1}\left(\mu^{2}+\sigma^{2}\right)-\alpha_{2} Q-b_{r} \mu-a_{r} \mu\right\} \\
& +\left(\beta_{2} Q+b_{r}\right) Q-\left(C_{s}-b_{r}\right) \int_{Q}^{\infty}(x-Q) f(x) d x
\end{aligned}
$$

Differentiating the above equation with respect to $Q$, we have as follows

$$
\begin{aligned}
& \frac{d \pi_{R}}{d Q}=-\alpha_{2}+b_{r}+2 \beta_{2} Q+\left(C_{s}-b_{r}\right) \int_{Q}^{\infty} f(x) d x \\
& \frac{d^{2} \pi_{R}}{d Q^{2}}=2 \beta_{2}-\left(C_{s}-b_{r}\right) f(Q)<0
\end{aligned}
$$

for $C_{s}>b_{r}$ and $f(Q)>\frac{2 \beta_{2}}{\left(C_{s}-b_{r}\right)}$. For maximum value of $\pi_{R}(Q), \frac{d \pi_{R}}{d Q}=0$, i.e., $\frac{2 \beta_{2}}{\left(C_{s}-b_{r}\right)} Q+\int_{Q}^{\infty} f(x) d x=\frac{\alpha_{2}-b_{r}}{\left(C_{s}-b_{r}\right)}$ must have a solution at $Q=Q^{*}$. Hence, we have the following proposition.

Proposition 1. The profit function $\pi_{R}(Q)$ attains its maximum at $Q^{*}$ if $\frac{2 \beta_{2}}{\left(C_{s}-b_{r}\right)} Q^{*}+\int_{Q^{*}}^{+\infty} f(x) d x=\frac{\alpha_{2}-b_{r}}{\left(C_{s}-b_{r}\right)}$ and $f\left(Q^{*}\right)>\frac{2 \beta_{2}}{\left(C_{s}-b_{r}\right)}$ hold simultaneously. Now using equations (3.2) and (3.3) in equation (3.6), we have

$$
\begin{gathered}
\pi_{S}(Q, R)=\left(\alpha_{2}-\beta_{2} Q-\alpha_{3}+\beta_{3} R-a_{1}\right) Q-h_{s} R / 2-a_{2} Q / R \\
-\left(b_{r}-b_{s}\right)(Q-\mu)-\left(b_{r}-b_{s}\right) \int_{Q}^{+\infty}(x-Q) f(x) d x
\end{gathered}
$$


As supplier is the follower of the retailer, the expected average profit at $Q=Q^{*}$ is $\pi_{S}\left(Q^{*}, R\right)=\left(\alpha_{2}-\beta_{2} Q^{*}-\alpha_{3}+\beta_{3} R-a_{1}\right) Q^{*}-\frac{1}{2} h_{s} R-\frac{a_{2} Q^{*}}{R}-\left(b_{r}-b_{s}\right)\left(Q^{*}-\right.$ $\mu)-\left(b_{r}-b_{s}\right) \int_{Q^{*}}^{+\infty}\left(x-Q^{*}\right) f(x) d x$. Then, the supplier will maximize his/her profit at optimal value of $R$. Now, differentiating $\pi_{S}\left(Q^{*}, R\right)$ with respect to $R$, we have

$$
\begin{aligned}
& \frac{d \pi_{S}\left(Q^{*}, R\right)}{d R}=\beta_{3} Q^{*}-\frac{1}{2} h_{s}+\frac{a_{2} Q^{*}}{R^{2}}, \\
& \frac{d^{2} \pi_{S}\left(Q^{*}, R\right)}{d R^{2}}=-\frac{2 a_{2} Q^{*}}{R^{3}}<0, \quad \forall R>0 .
\end{aligned}
$$

For maximum value of $\pi_{S}\left(Q^{*}, R\right), \frac{d \pi_{S}\left(Q^{*}, R\right)}{d R}=0$ provides a feasible solution $R^{*}=\sqrt{\frac{2 a_{2} Q^{*}}{h_{s}-2 \beta_{3} Q^{*}}}$ if $h_{s}>2 \beta_{3} Q^{*}$ holds. Hence, the following proposition is valid.

Proposition 2. The profit function $\pi_{S}\left(Q^{*}, R\right)$ attains its maximum value at $R^{*}=\sqrt{\frac{2 a_{2} Q^{*}}{h_{s}-2 \beta_{3} Q^{*}}}$ if $h_{s}>2 \beta_{3} Q^{*}$ holds.

\subsection{Centralized supply chain system}

In this chain, the supplier and retailer business jointly and their objective is to maximize their joint profit. In this collaborating system, the joint profit is

$$
\begin{gathered}
\pi_{C}(Q, R)=\pi_{R}+\pi_{S}=\left\{\alpha_{1} \mu-\beta_{1}\left(\mu^{2}+\sigma^{2}\right)-b_{s} \mu-a_{r} \mu\right\}+\left(-\alpha_{3}+\beta_{3} R\right. \\
\left.-a_{1}+b_{s}\right) Q-\frac{1}{2} h_{s} R-\frac{a_{2} Q}{R}-\left(C_{s}-b_{s}\right) \int_{Q}^{\infty}(x-Q) f(x) d x
\end{gathered}
$$

Differentiating $\pi_{C}(Q, R)$ with respect to $Q$ and $R$, we get

$$
\begin{aligned}
& \frac{\partial \pi_{C}}{\partial Q}=\left(-\alpha_{3}+\beta_{3} R-a_{1}+b_{s}\right)+\left(C_{s}-b_{s}\right) \int_{Q}^{\infty} f(x) d x, \\
& \frac{\partial \pi_{C}}{\partial R}=\beta_{3} Q-\frac{1}{2} h_{s}+\frac{a_{2} Q}{R^{2}}, \\
& \frac{\partial^{2} \pi_{C}}{\partial Q \partial R}=\frac{\partial^{2} \pi_{C}}{\partial R \partial Q}=\beta_{3}+\frac{a_{2}}{R^{2}}, \\
& \frac{\partial^{2} \pi_{C}}{\partial Q^{2}}=-\left(C_{s}-b_{s}\right) f(Q)<0 \text { as } C_{s}>b_{s}, \\
& \frac{\partial^{2} \pi_{C}}{\partial R^{2}}=-\frac{2 a_{2} Q}{R^{3}}<0, \quad \forall R>0 .
\end{aligned}
$$

Now, solving $\frac{\partial \pi_{C}}{\partial Q}=0=\frac{\partial \pi_{C}}{\partial R}$, we have the stationary point $\left(Q^{*}, R^{*}\right)$ such that $R^{*}\left(Q^{*}\right)=\sqrt{\frac{2 a_{2} Q^{*}}{h_{s}-2 \beta_{3} Q^{*}}} \&\left(-\alpha_{3}+\beta_{3} R^{*}\left(Q^{*}\right)-a_{1}+b_{s}\right)+\left(C_{s}-b_{s}\right) \int_{Q^{*}}^{\infty} f(x) d x=0$.

Therefore, $\pi_{C}(Q, R)$ has maximum value at $\left(Q^{*}, R^{*}\right)$ if $\left[\left(\frac{\partial^{2} \pi_{C}}{\partial Q^{2}}\right)\left(\frac{\partial^{2} \pi_{C}}{\partial R^{2}}\right)\right.$ $\left.-\left(\frac{\partial^{2} \pi_{C}}{\partial Q \partial R}\right)^{2}\right]>0$, i.e., $2 a_{2} Q^{*} R^{*}\left(C_{s}-b_{s}\right) f\left(Q^{*}\right)>\left(R^{* 2} \beta_{3}+a_{2}\right)^{2}$ holds. Hence, we have the following proposition. 
Proposition 3. If $\left(-\alpha_{3}+\beta_{3} R^{*}\left(Q^{*}\right)-a_{1}+b_{s}\right)+\left(C_{s}-b_{s}\right) \int_{Q^{*}}^{\infty} f(x) d x=0$ has solution $Q^{*} \in\left(0, \frac{h_{s}}{2 \beta_{3}}\right)$ and $2 a_{2} Q^{*} R^{*}\left(C_{s}-b_{s}\right) f\left(Q^{*}\right)>\left(R^{* 2} \beta_{3}+a_{2}\right)^{2}$ holds, then $\pi_{C}(Q, R)$ attains maximum at $\left(Q^{*}, R^{*}\right)$.

\subsection{Distribution free case}

In this case, probability distribution of demand of the end customers is unknown. Then, the above problem may be approximated to a function where mean and standard deviation are used instead of probability density function as it is not defined. Using the inequality

$$
\int_{Q}^{\infty}(x-Q) f(x) d x=E(x-Q)^{+} \leq \frac{1}{2}\left\{\sqrt{\sigma^{2}+(Q-\mu)^{2}}-(Q-\mu)\right\}
$$

in equation (3.7), we have

$$
\begin{aligned}
& \pi_{C}(Q, R) \geq\left\{\alpha_{1} \mu-\beta_{1}\left(\mu^{2}+\sigma^{2}\right)-b_{s} \mu-a_{r} \mu\right\}+\left(-\alpha_{3}+\beta_{3} R-a_{1}+b_{s}\right) Q \\
& -\frac{1}{2} h_{s} R-\frac{a_{2} Q}{R}-\left(C_{s}-b_{s}\right) \frac{1}{2}\left\{\sqrt{\sigma^{2}+(Q-\mu)^{2}}-(Q-\mu)\right\}=Y(Q, R) .
\end{aligned}
$$

Now our aim is to maximize $Y(Q, R)$. Differentiating partially with respect to $Q$ and $R$, we have

$$
\begin{aligned}
& \frac{\partial Y}{\partial Q}=\left(-\alpha_{3}+\beta_{3} R-a_{1}+b_{s}\right)+\frac{1}{2}\left(C_{s}-b_{s}\right)\left\{\frac{Q-\mu}{\sqrt{\sigma^{2}+(Q-\mu)^{2}}}-1\right\}, \\
& \frac{\partial Y}{\partial R}=\beta_{3} Q-\frac{1}{2} h_{s}+\frac{a_{2} Q}{R^{2}}, \frac{\partial Y}{\partial Q \partial R}=\frac{\partial Y}{\partial R \partial Q}=\beta_{3}+\frac{a_{2}}{R^{2}}, \\
& \frac{\partial^{2} Y}{\partial Q^{2}}=-\frac{1}{2}\left(C_{s}-b_{s}\right)\left[\frac{\sigma^{2}}{\left(\sigma^{2}+(Q-\mu)^{2}\right)^{3 / 2}}\right]<0 \text { as } C_{s}>b_{s}, \\
& \frac{\partial^{2} Y}{\partial R^{2}}=-\frac{2 a_{2} Q}{R^{3}}<0, \quad \forall R>0 .
\end{aligned}
$$

Now, solving $\frac{\partial Y}{\partial Q}=0=\frac{\partial Y}{\partial R}$, we have the stationary point $\left(Q^{*}, R^{*}\right)$ such that $R^{*}\left(Q^{*}\right)=\sqrt{2 a_{2} Q^{*} /\left(h_{s}-2 \beta_{3} Q^{*}\right)}$ and

$$
\left(-\alpha_{3}+\beta_{3} R^{*}\left(Q^{*}\right)-a_{1}+b_{s}\right)+\frac{1}{2}\left(C_{s}-b_{s}\right)\left\{\frac{Q^{*}-\mu}{\sqrt{\sigma^{2}+\left(Q^{*}-\mu\right)^{2}}}-1\right\}=0 .
$$

Therefore, $Y(Q, R)$ has maximum value at $\left(Q^{*}, R^{*}\right)$ if $\left[\left(\frac{\partial^{2} Y}{\partial Q^{2}}\right)\left(\frac{\partial^{2} Y}{\partial R^{2}}\right)-\left(\frac{\partial^{2} Y}{\partial Q \partial R}\right)^{2}\right]>$ 0, i.e., $2 a_{2} Q^{*} R^{*}\left\{\frac{1}{2}\left(C_{s}-b_{s}\right)\left(\frac{\sigma^{2}}{\left(\sigma^{2}+(Q-\mu)^{2}\right)^{3 / 2}}\right)\right\}>\left(R^{* 2} \beta_{3}+a_{2}\right)^{2}$ holds. Hence, we have the following proposition.

Proposition 4. If $\left(-\alpha_{3}+\beta_{3} R^{*}\left(Q^{*}\right)-a_{1}+b_{s}\right)+\frac{1}{2}\left(C_{S}-b_{s}\right)\left\{\frac{Q^{*}-\mu}{\sqrt{\sigma^{2}+\left(Q^{*}-\mu\right)^{2}}}-\right.$ $1\}=0$ has solution $Q^{*} \in\left(0, \frac{h_{s}}{2 \beta_{3}}\right)$ and $2 a_{2} Q^{*} R^{*}\left\{\frac{1}{2}\left(C_{s}-b_{s}\right)\left(\frac{\sigma^{2}}{\left(\sigma^{2}+(Q-\mu)^{2}\right)^{3 / 2}}\right)\right\}>$ $\left(R^{* 2} \beta_{3}+a_{2}\right)^{2}$ holds, then $\pi_{C}(Q, R)$ attains maximum at $\left(Q^{*}, R^{*}\right)$. 


\subsection{Discrete distribution}

Here, the demand of end customer is $i(i=1,2, \ldots)$ unit with probability $f_{i}$ such that $\sum_{i=1}^{\infty} f_{i}=1$ and $\sum_{i=1}^{\infty} i f_{i}=\mu$. The order quantity of the retailer is $j(j=1,2, \ldots)$ unit. Then, the expected profits of the retailer and supplier are

$$
\begin{aligned}
& \pi_{R}^{j}=\sum_{i=1}^{\infty} p(i) i f_{i}+b_{r} \sum_{i=1}^{j}(j-i) f_{i}-a_{r} \sum_{i=1}^{\infty} i f_{i}-C_{s} \sum_{i=j+1}^{\infty}(i-j) f_{i}-w(j) j, \\
& \pi_{S}^{R}=(w(j)-C(R)) j-\frac{1}{2} h_{s} R-a_{1} j-\frac{a_{2} j}{R}-\left(b_{r}-b_{s}\right) \sum_{i=1}^{j}(j-i) f_{i} .
\end{aligned}
$$

In decentralized system, the retailer first optimizes his/her profit and finds out optimal order size $j$. Then, the supplier optimizes his/her profit following order size $j$ and determines the replenishment size $R$. Now, $\pi_{R}^{j}-\pi_{R}^{j+1}>0$ implies $\sum_{i=1}^{j} f_{i}-\left(\frac{2 \beta_{2}}{C_{s}-b_{r}}\right) j>\left(\frac{C_{s}-\alpha_{2}+\beta_{2}}{C_{s}-b_{r}}\right)$ and $\pi_{R}^{j}-\pi_{R}^{j-1}>0$ implies $\sum_{i=1}^{j-1} f_{i}-$ $\left(\frac{2 \beta_{2}}{C_{s}-b_{r}}\right)(j-1)<\left(\frac{C_{s}^{s}-\alpha_{2}+\beta_{2}}{C_{s}-b_{r}}\right)$. Therefore, $q^{*}=j$ is optimum lot size if $\pi_{R}^{j-1}<$ $\pi_{R}^{j}>\pi_{R}^{j+1}$, i.e.,

$$
\sum_{i=1}^{j-1} f_{i}-\left(\frac{2 \beta_{2}}{C_{s}-b_{r}}\right)(j-1)<\left(\frac{C_{s}-\alpha_{2}+\beta_{2}}{C_{s}-b_{r}}\right)<\sum_{i=1}^{j} f_{i}-\left(\frac{2 \beta_{2}}{C_{s}-b_{r}}\right) j
$$

holds. Now, our objective is to maximize $\pi_{S}^{R}\left(j=q^{*}\right)$ for $R \in Z^{+}$. Here, $\pi_{S}^{R}$ provides maximum value at $R$ if the inequality $\pi_{S}^{R-1}<\pi_{S}^{R}>\pi_{S}^{R+1}$ holds, i.e., $R(R-1)<2 a_{2} q^{*} /\left(h_{s}-2 \beta_{3} q^{*}\right)<R(R+1)$ holds. In collaborating system, the joint profit is

$$
\begin{array}{r}
\pi_{c}(j, R)=\sum_{i=1}^{\infty} p(i) i f_{i}-a_{r} \sum_{i=1}^{\infty} i f_{i}-C_{s} \sum_{i=j+1}^{\infty}(i-j) f_{i} \\
-C(R) j-\frac{1}{2} h_{s} R-a_{1} j-\frac{a_{2} j}{R}+b_{s} \sum_{i=1}^{j}(j-i) f_{i} .
\end{array}
$$

Let $R=k j(k>0)$, then the profit function $\pi_{c}(j)$ is maximum at $j$ if the inequality $\pi_{c}(j-1)<\pi_{c}(j)>\pi_{c}(j+1)$, i.e., the inequality $\phi(j-1)<$ $\alpha_{3}-\beta_{3} k+\frac{1}{2} h_{s} k+a_{1}<\phi(j)$ holds where $\phi(j)=b_{s} \sum_{i=1}^{j} f_{i}+2 \beta_{3} k j$. Varying the value of $k$, we may find out an optimum value of $k$ such that the joint profit is maximized.

\section{Numerical Examples}

\subsection{Example 1}

We consider the values of parameters in appropriate units for continuous distribution function as follows: $\alpha_{1}=50, \alpha_{2}=30, \alpha_{3}=10, \beta_{1}=0.10, \beta_{2}=0.15$, $\beta_{3}=0.01, a_{r}=0.25, a_{1}=0.25, a_{2}=100, h_{s}=2, b_{r}=5, b_{s}=4, C_{s}=25$, $\mu=50$ and $\sigma=5$. The demand of end customers follows normal distribution 
function $f(x)=\frac{1}{\sigma \sqrt{2 \pi}} e^{-\frac{1}{2}\left(\frac{x-\mu}{\sigma}\right)^{2}}, \forall x \in(-\infty,+\infty)$ such that $\int_{-\infty}^{+\infty} f(x) d x=1$. If retailer is Stakellberg leader and supplier is the follower of retailer, then the optimal solutions are $Q^{*}=49.9984, R^{*}=99.9968, \pi_{R}^{*}=1070.11, \pi_{S}^{*}=510.49$ and the total profit of the chain is $\pi_{c}^{*}=\left(\pi_{R}^{*}+\pi_{S}^{*}\right)=1580.60$. In centralized system, the optimal solutions are $Q^{*}=53.4251, R^{*}=107.102, \pi_{c}^{*}=1585.94$ which is better than the decentralized system. In centralized system, the profit is distributed according to their investment in the chain, i.e., the expected profit of retailer is equal to $\pi_{c}^{*}\left(\frac{\text { expected cost of retailer }}{\text { expected cost of the whole chain }}\right)$ and expected profit of supplier is equal to $\pi_{c}^{*}\left(\frac{\text { expected cost of supplier }}{\text { expected cost of the whole chain }}\right)$. At the optimal values of $\mathrm{Q}$ and R, the expected cost of retailer, supplier and whole chain are 1143.81, 654.80 and 1798.61. The expected profits of retailer and supplier are 1008.56 and 577.38 respectively. In this collaborating system, agreement of buyback and delivery in due time are strictly followed by retailer and supplier. The expected profits of the retailer (Figure 1(a)) and expected profit of the supplier (Figure 1(b)) in decentralized system are concave functions.

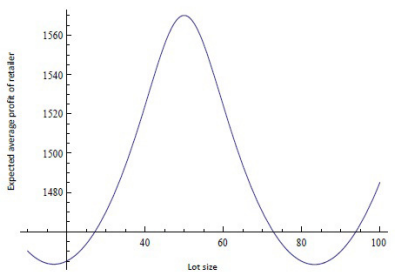

a)

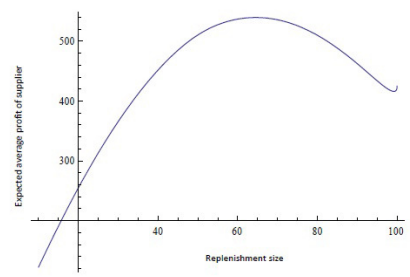

b)

Figure 1. Expected average profits: a) $\pi_{R}$ of the retailer versus lot size $(Q)$, b) $\pi_{S}$ of the supplier versus replenishment size $(R)$.

Also, Figure 2(a) shows concavity of the expected profit of the chain in centralized system.

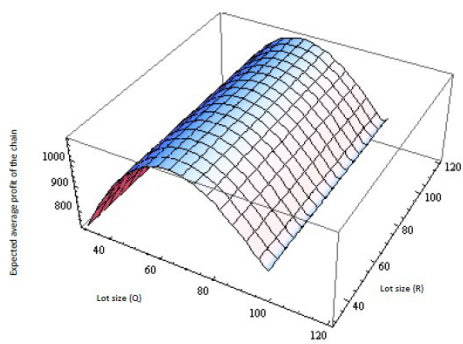

a)

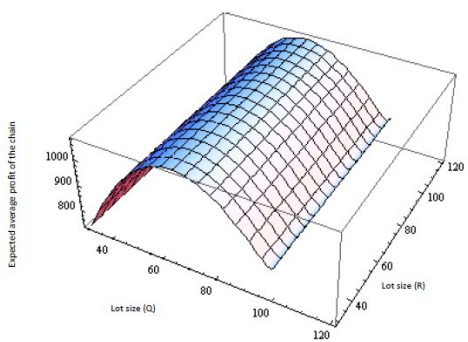

b)

Figure 2. Expected average profits: a) $\pi_{c}$ of collaborating system versus lot size $(Q)$ and replenishment size $(R)$ in case of normal distribution, b) $\left(\pi_{c}\right)$ of collaborating system versus lot size $(Q)$ and replenishment size $(R)$ in case of distribution free. 
In distribution free case of centralized system, values of all parameters are same as Example 4.1. Then, the optimal solutions are $Q^{*}=97.5481$, $R^{*}=630.758, \pi_{c}^{*}=1391.64$. Here, Figure $2(\mathrm{~b})$ shows clearly concavity of the expected profit of the chain.

\subsection{Example 2}

For discrete distribution of demand of end customers, we consider probability of occurrence of $i$ unit as $f_{i}$ that follows Poisson distribution $f_{i}=\frac{\mu^{i} e^{-\mu}}{i !},(i=$ $1,2, \ldots$ In this case, values of all parameters are considered as same as Example 4.1. If retailer is decision maker and supplier is the follower of retailer, then the optimal solutions are $Q^{*}=j=52, R^{*}=104, \pi_{R}^{*}=1039.44, \pi_{S}^{*}=517.53$ and the total profit of the chain is $\pi_{c}^{*}=\left(\pi_{R}^{*}+\pi_{S}^{*}\right)=1556.97$. In centralized system, the optimal solutions are $k^{*}=2, Q^{*}=j=55, R^{*}=110, \pi_{c}^{*}=1563.49$ which is larger than the decentralized system.

The above conjectures involved in the proposed model are observed in retailing systems of fashion/textiles products. In this supply chain, if the members of the channel stock too much that result in higher cost for holding huge stock but can recover some salvage value for the excess stock. On the other hand, if any member stocks too little, he/she loses profit as well as goodwill from the downstream members. In such stock out situation, she/he has to satisfy the downstream members at expensive cost from alternative sources. As the demand is uncertain in nature, each member of the chain has to quantify how much to stock to best fit supply with demand. The proposed model suggests to the managers of the retailer and the supplier to find out optimum order quantities based on the forecast of the demand of the downstream members, selling prices and cost factors so that the profit of each member is maximized. Quite often, forecasting of future demand of commodities is quite difficult as the demand is not deterministic. In this case, suitable probability distribution of the demand function based on prior knowledge of distribution is very important issue. Our model helps the management to choose the suitable scenario among three models (continuous distribution, discrete distribution and distribution free cases) based on the features of the market.

\section{Conclusions}

The newsvendor problem is one of the classical problems in inventory literature. In this problem, no cost for inventory is taken into account if the ordered quantity is less than the demand but penalty cost of shortage is considered in stock out situation. Several authors have extended this problem incorporating several issues. The objective of this proposed article is to extend the analysis of the problem of a supply chain of supplier and retailer for uncertain demand of the end customers. This model considers several issues like as buyback policy, variable costs and profit per unit item those are monotonic decreasing functions of ordered sizes. Quite often, the purchasing costs (i.e., price break) of the units of the channel members depend on the lot sizes. The problems of individual and joint/collaborative model of the channel members are well 
analyzed and the numerical results show that the collaborating system always provides better results than the individual profit of the channel members. Here, the joint profit of the chain is distributed over the members according to their contribution in the chain. Our model analyzes the problems both for continuous and discrete distribution of the demand. Moreover, the distribution free case is studied while demand does not follow any known distribution function. In such situation, the mean and standard deviation are measured using prior knowledge of data of the business organization. The proposed model helps to the management of decision makers of the chain how much quantities of the product would be ordered by the supplier and the retailer so that the joint profit is maximized. As far as the knowledge of the authors goes, such model of news-vendor in supply chain including several issues has yet been studied in previous literature.

The proposed model considers two echelon (retailer and supplier) supply chain with deterministic cost factors for single item only. These limitations can be waived by considering multi-echelon supply chain for multi-items with variable cost factors. Our model could be extended immediately for substitute and complementary products implementing dual channel (online and offline) marketing system which are more relevant in fashion /textile industries. In future research, one can study our model by various game theories including pricing competition, i.e., price bargaining among the channel members both in vertical and horizontal levels of multi-echelon supply chain.

\section{References}

[1] G. Cai. Channel selection and coordination in dual-channel supply chains. Journal of Retailing, 86(1):22-36, 2010. https://doi.org/10.1016/j.jretai.2009.11.002. Available from Internet: http://www.sciencedirect.com/science/article/ pii/S0022435909000864.

[2] L.E. Cárdenas-Barrón, K.-J. Chung and G. Treviño-Garza. Celebrating a century of the economic order quantity model in honor of Ford Whitman Harris. International Journal of Production Economics, 155:1 - 7, 2014. https://doi.org/10.1016/j.ijpe.2014.07.002.

[3] L.E. Cárdenas-Barrón, A.A. Taleizadeh and G. Treviño-Garza. An improved solution to replenishment lot size problem with discontinuous issuing policy and rework, and the multi-delivery policy into economic production lot size problem with partial rework. Expert Systems with Applications, 39(18):13540-13546, 2012. https://doi.org/10.1016/j.eswa.2012.07.012.

[4] L.E. Cárdenas-Barrón, G. Treviño-Garza, G.A. Widyadana and H.-M. Wee. A constrained multi-products EPQ inventory model with discrete delivery order and lot size. Applied Mathematics and Computation, 230(Complete):359-370, 2014. https://doi.org/10.1016/j.amc.2013.12.077.

[5] M.S. Chen and C.C. Chuang. An extended newsboy problem with shortagelevel constraints. International Journal of Production Economics, 67(3):269-277, 2000. https://doi.org/10.1016/S0925-5273(00)00025-6.

[6] C.J. Chung and H.-M. Wee. An integrated production-inventory deteriorating model for pricing policy considering imperfect production, 
inspection planning and warranty-period- and stock-level-dependant demand. International Journal of Systems Science, 39(8):823-837, 2008. https://doi.org/10.1080/00207720801902598.

[7] K.-J. Chung, L.E. Cárdenas-Barrón and P.-S. Ting. An inventory model with non-instantaneous receipt and exponentially deteriorating items for an integrated three layer supply chain system under two levels of trade credit. International Journal of Production Economics, 155:310-317, 2014. https://doi.org/10.1016/j.ijpe.2013.12.033.

[8] M.Y. Jaber, I.H. Osman and A.L. Guiffrida. Coordinating a three-level supply chain with price discounts, price dependent demand, and profit sharing. International Journal of Integrated Supply Management, 2(1/2):1660-1672, 2006. https://doi.org/10.1504/IJISM.2006.008337.

[9] M. Khan, M. Hussain and L.E. Cárdenas-Barrón. Learning and screening errors in an EPQ inventory model for supply chains with stochastic lead time demands. International Journal of Production Research, 55(16):4816-4832, 2017. https://doi.org/10.1080/00207543.2017.1310402.

[10] S. Khanra, B. Mandal and B. Sarkar. A comparative study between inventory followed by shortages and shortages followed by inventory under trade-credit policy. International Journal of Applied and Computational Mathematics, 1(3):399-426, 2015. https://doi.org/10.1007/s40819-015-0024-z.

[11] Sh-T. Lo, H.-M. Wee and W.-C. Huang. An integrated production-inventory model with imperfect production processes and Weibull distribution deterioration under inflation. International Journal of Production Economics, 106(1):248-260, 2007. https://doi.org/10.1016/j.ijpe.2006.06.009.

[12] L. Ma, W. Xue, Y. Zhao and Q. Zeng. Loss-averse newsvendor problem with supply risk. Journal of the Operational Research Society, 67(2):214-228, 2016. https://doi.org/10.1057/jors.2015.22.

[13] C.L. Munson and M.J. Rosenblatt. Coordinating a three-level supply chain with quantity discounts. IIE Transactions, 33(5):371-384, 2001. https://doi.org/10.1080/07408170108936836.

[14] S. Panda. Coordinating two-echelon supply chains under stock and price dependent demand rate. Asia-Pacific Journal of Operational Research, 30(02):1250051, 2013. https://doi.org/10.1142/S0217595912500510.

[15] S. Panda. Coordination of a socially responsible supply chain using revenue sharing contract. Transportation Research Part E: Logistics and Transportation Review, 67:92-104, 2014. https://doi.org/10.1016/j.tre.2014.04.002.

[16] S. Panda, N.M. Modak and L.E. Cárdenas-Barrón. Coordination and benefit sharing in a three-echelon distribution channel with deteriorating product. Computers \& Industrial Engineering, 113:630-645, 2017. https://doi.org/10.1016/j.cie.2017.09.033.

[17] S. Y Park and H.T. Keh. Modelling hybrid distribution channels: a gametheoretic analysis. Journal of Retailing and Consumer Services, 10(3):155-167, 2003. https://doi.org/10.1016/S0969-6989(03)00007-9.

[18] N.C. Petruzzi and M. Dada. Pricing and the newsvendor problem: A review with extensions. Operations Research, 47(2):183-194, 1999. https://doi.org/10.1287/opre.47.2.183. 
[19] S.S. Sana. The stochastic EOQ model with random sales price. Applied Mathematics and Computation, 218(2):239-248, 2011. https://doi.org/10.1016/j.amc.2011.05.015.

[20] S.S. Sana. A collaborating inventory model in a supply chain. Economic Modelling, 29(5):2016-2023, 2012. https://doi.org/10.1016/j.econmod.2012.04.021.

[21] B. Sarkar. A production-inventory model with probabilistic deterioration in twoechelon supply chain management. Applied Mathematical Modelling, 37(5):31383151, 2013. https://doi.org/10.1016/j.apm.2012.07.026.

[22] B. Sarkar. Supply chain coordination with variable backorder, inspections, and discount policy for fixed lifetime products. Mathematical Problems in Engineering, 2016:14, 2016. https://doi.org/10.1155/2016/6318737.

[23] B. Sarkar and A. Majumder. Integrated vendor-buyer supply chain model with vendor's setup cost reduction. Applied Mathematics and Computation, 224:362371, 2013. https://doi.org/10.1016/j.amc.2013.08.072.

[24] N.H. Shah, A.S. Gor and C.A. Jhaveri. Optimal pricing and ordering policy for an integrated inventory model with quadratic demand when trade credit linked to order quantity. Journal of Modelling in Management, 7(2):148-165, 2012. https://doi.org/10.1108/17465661211242787.

[25] N.H. Shah and K.T. Shukla. Optimal production schedule in declining market for an imperfect production system. International Journal of Machine Learning and Cybernetics, 1(1):89-99, 2010. https://doi.org/10.1007/s13042-010-0005-9.

[26] A.A. Taleizadeh, M. Noori-daryan and L.E. Cárdenas-Barrón. Joint optimization of price, replenishment frequency, replenishment cycle and production rate in vendor managed inventory system with deteriorating items. International Journal of Production Economics, 159:285-295, 2015. https://doi.org/10.1016/j.ijpe.2014.09.009.

[27] A.A. Taleizadeh, H.-M. Wee and S.J. Sadjadi. Multi-product production quantity model with repair failure and partial backordering. Computers $\&$ Industrial Engineering, 59(1):45-54, 2010. https://doi.org/10.1016/j.cie.2010.02.015.

[28] Muhammad Tayyab and Biswajit Sarkar. Optimal batch quantity in a cleaner multi-stage lean production system with random defective rate. Journal of Cleaner Production, 139:922-934, 2016. https://doi.org/10.1016/j.jclepro.2016.08.062.

[29] B. van der Rhee, J.A.A. van der Veen, V. Venugopal and V.R. Nalla. A new revenue sharing mechanism for coordinating multiechelon supply chains. Operations Research Letters, 38(4):296-301, 2010. https://doi.org/10.1016/j.orl.2010.03.004.

[30] C.-H. Wang. Some remarks on an optimal order quantity and reorder point when supply and demand are uncertain. Computers $\mathcal{E}$ Industrial Engineering, 58(4):809-813, 2010. https://doi.org/10.1016/j.cie.2010.01.010.

[31] H.M. Wee and P.C. Yang. The optimal and heuristic solutions of a distribution network. European Journal of Operational Research, 158(3):626 - 632, 2004. https://doi.org//10.1016/S0377-2217(03)00383-7.

[32] D.-Q. Yao, X. Yue, X. Wang and J.J. Liu. The impact of information sharing on a returns policy with the addition of a direct channel. International Journal of Production Economics, 97(2):196-209, 2005. https://doi.org/10.1016/j.ijpe.2004.08.006. 